Research Article

\title{
Procalcitonin Levels in Patients with Complete and Incomplete Kawasaki Disease
}

\author{
Hwa Jin Cho, Young Earl Choi, Eun Song Song, Young Kuk Cho, and Jae Sook Ma \\ Department of Pediatrics, Chonnam National University Hospital, Chonnam National University Medical School, \\ 8 Hakdong, Dong-gu, Gwangju 501-757, Republic of Korea \\ Correspondence should be addressed to Young Kuk Cho; youngcx@hanmail.net and Jae Sook Ma; cardiol@jnu.ac.kr
}

Received 15 July 2013; Revised 10 September 2013; Accepted 16 September 2013

Academic Editor: Natacha Turck

Copyright (C) 2013 Hwa Jin Cho et al. This is an open access article distributed under the Creative Commons Attribution License, which permits unrestricted use, distribution, and reproduction in any medium, provided the original work is properly cited.

Incomplete Kawasaki disease (iKD) is considered to be a less complete form of Kawasaki disease (cKD), and several differences in the laboratory presentations of $\mathrm{iKD}$ and $\mathrm{cKD}$ have been noted. We investigated serum procalcitonin levels in patients with iKD, cKD, and other febrile diseases (a control group). Seventy-seven patients with cKD, 24 with iKD, and 41 controls admitted to our hospital from November 2009 to November 2011 were enrolled in the present study. We obtained four measurements of serum procalcitonin levels and those of other inflammatory markers from each patient. Samples were taken for analysis on the day of diagnosis (thus before treatment commenced; D0) and 2 (D2), 14 (D14), and 56 days (D56) after intravenous immunoglobulin infusion. We obtained control group data at D0. The mean D0 serum procalcitonin levels of cKD patients $(0.71 \pm 1.36 \mathrm{ng} / \mathrm{mL})$ and controls $(0.67 \pm 1.06 \mathrm{ng} / \mathrm{mL})$ were significantly higher than those of $\mathrm{iKD}$ patients $(0.26 \pm 0.26 \mathrm{ng} / \mathrm{mL})(P=0.014$ and $P=0.041$, resp.). No significant difference in mean procalcitonin level was evident among groups at any subsequent time. In conclusion, the serum procalcitonin level of patients with acute-stage $\mathrm{CKD}$ was significantly higher than that of iKD patients.

\section{Introduction}

Kawasaki disease (KD) is a form of systemic vasculitis, the etiology of which is unknown. No definitive diagnostic laboratory test exists $[1,2]$. Diagnosis is based on clinical signs raising suspicion of the disease, including fever of over 5 days in duration and at least four of the following five symptoms: bilateral bulbar conjunctival infection, changes in the oral mucosa, changes in the peripheral extremities, polymorphous rash, and cervical adenopathy more than $1.5 \mathrm{~cm}$ in diameter [3].

Complete $\mathrm{KD}(\mathrm{cKD})$ is diagnosed if all diagnostic criteria are fulfilled, whereas incomplete $\mathrm{KD}$ (iKD), which occurs in $15-20 \%$ of $\mathrm{KD}$ patients, is diagnosed when not all clinical features are present provided that several suspicious features are evident, laboratory findings suggest the presence of $\mathrm{KD}$, and alternative diagnoses have been excluded [4]. Because only some (thus not all) clinical symptoms typical of cKD are apparent, iKD diagnosis can be delayed $[5,6]$, and such delay is a risk factor for development of coronary artery lesions $[7,8]$.
Although $\mathrm{iKD}$ is considered to be an incomplete form of $\mathrm{cKD}$, because $\mathrm{iKD}$ and $\mathrm{CKD}$ patient demographic and laboratory findings are similar $[9,10]$, several differences in clinical and laboratory presentations have been described. Relatively more children with $\mathrm{iCD}$ are found at the extremes of the childhood age spectrum ( $\leq 1$ year of age, or 5-9 years old), and low levels of both serum alanine aminotransferase (ALT) and gamma-glutamyltransferase and low proportions of hyponatremia and pyuria have been reported in children with iKD $[11,12]$.

Procalcitonin is a peptide precursor of calcitonin, the level of which increases in response to proinflammatory stimuli, especially those of bacterial origin. Procalcitonin levels $>5 \mathrm{ng} / \mathrm{mL}$ are closely associated with the presence of severe infection, usually bacteremia [13]. Various procalcitonin levels have been reported in patients with KD. Okada et al. [14] found that patients with $\mathrm{KD}$ had serum procalcitonin levels significantly higher than normal and bacterial infections occurred more frequently in KD patients compared to those with autoimmune diseases or viral infections, or healthy children. The cited authors also found that four patients who 
developed coronary aneurysms had elevated procalcitonin levels. In contrast, Chakrabartty and Apong reported that all $38 \mathrm{KD}$ patients studied had low procalcitonin levels $(<0.5 \mathrm{ng} / \mathrm{mL})$ but elevated C-reactive protein (CRP) concentrations and erythrocyte sedimentation rates (ESRs) [15]. To date, no report examining possible differences in procalcitonin levels between patients with $\mathrm{CKD}$ and $\mathrm{iKD}$ has appeared. We therefore measured the serum concentrations of procalcitonin in such patients and compared these levels with those of patients with other febrile illnesses.

\section{Materials and Methods}

2.1. Patients. We enrolled child patients admitted to Chonnam National University Hospital from November 2009 to November 2011. Informed written consent was obtained from the parents of all patients. A total of 101 patients diagnosed with KD were enrolled. Of these, 77 were diagnosed with $\mathrm{cKD}$ and 24 with iKD. cKD was diagnosed if all diagnostic criteria were fulfilled [3]. iKD was diagnosed if fewer than three diagnostic criteria were met (although the presence of fever was required); the laboratory findings were typical of $\mathrm{KD}$ patients; and no alternative diagnosis was apparent [3]. We also enrolled 41 patients (controls) with other febrile diseases. These patients had experienced more than 3 days of fever, ranged in age from 3 months to 7 years, and had elevated CRP $(>2.0 \mathrm{mg} / \mathrm{dL})$ levels. We excluded potential controls with known congenital heart disease or clinically recognizable myocarditis.

2.2. Two-Dimensional Echocardiography. We performed twodimensional echocardiography on four occasions on each $\mathrm{KD}$ patient: on the day of diagnosis (prior to treatment; D0) and 2 (D2), 14 (D14), and 56 days (D56) after intravenous immunoglobulin (IVIG) infusion. We checked all scans for the presence of pericardial effusion, coronary artery lesions, and mitral regurgitation, and we assessed left ventricular function including the ejection fraction (EF). Both the electrocardiographic rhythm and the heart rate were monitored during each examination. The size of each coronary artery was converted to a $z$-score to compare dilatation among individuals. A coronary artery lesion was regarded as present if the $z$-scores were $\geq 2.5$ for both the proximal right coronary artery and the left anterior descending artery [16].

2.3. Peripheral Venous Blood Examination. Peripheral venous blood was drawn to measure serum procalcitonin levels in cKD and iKD patients and controls. We also obtained complete blood cell counts and ESRs and measured the levels of CRP, total protein, albumin, sodium, blood urea nitrogen (BUN), creatinine, aspartate aminotransferase (AST), ALT, creatine kinase (CK), CK-MB, myoglobin, troponin-I, and $\mathrm{N}$-terminal pro-brain natriuretic peptide (NT-proBNP). We measured serum procalcitonin levels on four occasions in each KD patient: at D0, D2, D14, and D56. Control data were collected only during the acute stage of disease (D0). We compared the $\mathrm{D} 0$ values of the $\mathrm{cKD}, \mathrm{iKD}$, and control groups and those from $\mathrm{CKD}$ and $\mathrm{iKD}$ patients gathered at later
TABLE 1: Demographic characteristics of patients with complete Kawasaki disease (cKD), incomplete KD (iKD), and other infectious diseases (controls).

\begin{tabular}{lcccc}
\hline & Complete & Incomplete & Control & \\
& KD & KD & & \\
& $n=77$ & $n=24$ & $n=41$ & \\
& & & \\
\hline $\begin{array}{l}\text { Age (years; mean } \pm \text { SD) } \\
\text { Gender (M/F) }\end{array}$ & $2.5 \pm 1.9$ & $2.1 \pm 2.4$ & $2.8 \pm 1.9$ & 0.451 \\
$\begin{array}{l}\text { Duration of fever } \\
\text { (days; mean } \pm \text { SD) }\end{array}$ & $52 / 25$ & $15 / 9$ & $28 / 13$ & 0.662 \\
$\begin{array}{l}\text { Duration of fever } \\
\text { prior to admission } \\
\text { (days; mean } \pm \text { SD) }\end{array}$ & $4.1 \pm 1.9$ & $5.6 \pm 1.1$ & $6.3 \pm 3.7$ & 0.815 \\
\hline
\end{tabular}

KD: Kawasaki disease.

times. Serum NT-proBNP was analyzed using an electrochemiluminescence immunoassay (Elecsys ProBNP Sandwich Immunoassay; Roche Diagnostics, Basel, Switzerland). Serum procalcitonin levels were quantitated by immunoassay (Elecsys BRAHMS PCT Procalcitonin, Roche). The lower and maximum limits of detection were 0.02 and $100 \mathrm{ng} / \mathrm{mL}$, respectively.

2.4. Statistical Analysis. The chi-squared test was used to assess the statistical significance of differences in the values of independent variables, and analysis of variance (ANOVA), followed by application of Tukey's post hoc test, was employed to compare data among the three groups. Two-way repeatedmeasures ANOVA followed by use of Tukey's post hoc test was employed for intragroup analysis. Continuous variables were expressed as means \pm standard deviations. A probability of $<0.05$ was considered to indicate statistical significance. The software package SPSS (version 20.0; SPSS, Chicago, IL) was used for all data analysis.

2.5. Ethics Statement. The present study was approved by the Institutional Review Board of Chonnam National University Hospital (Protocol no. I-2009-09-103). All data were treated confidentially.

\section{Results}

3.1. Patients' Characteristics. Patient demographics are shown in Table 1. Seventy-seven cKD patients were enrolled; the male-to-female ratio was 2.08. Mean patient age was $2.5 \pm$ 1.9 years (range, 5 months to 6.8 years) and the mean body weight $13.5 \pm 3.8 \mathrm{~kg}$. Twenty-four iKD patients were enrolled, and the male-to-female ratio was 1.7. Mean patient age was $2.1 \pm 2.4$ years (range, 3 months to 10 years) and the mean body weight $16.5 \pm 11.0 \mathrm{~kg}$. The proportion of patients at the age extremes ( $<1$ year or $\geq 5$ years) in the iKD group $(n=14$, $58.3 \%)$ was higher than in the cKD group $(n=27,35.0 \%)$ $(P=0.043)$.

All KD patients (those with either $\mathrm{CKD}$ or $\mathrm{iKD}$ ) were treated with $2 \mathrm{~g} / \mathrm{kg}$ intravenous immunoglobulin (IVIG) given as a single infusion. All patients were prescribed $30-$ $50 \mathrm{mg} / \mathrm{kg}$ oral aspirin during the acute inflammatory stage, 
TABLE 2: Clinical features and echocardiographic findings in patients with complete and incomplete Kawasaki disease (KD).

\begin{tabular}{lccc}
\hline & Complete KD & Incomplete KD \\
$n=24$ & & $P$ value \\
\hline Classic clinical presentations & & $21(87.0 \%)$ & 0.178 \\
Bilateral bulbar conjunctival infection & $74(96.0 \%)$ & $15(62.0 \%)$ & 0.007 \\
Polymorphous rash & $71(92.0 \%)$ & $18(75.0 \%)$ & 0.032 \\
Changes in oral mucosa & $73(94.0 \%)$ & $7(29.0 \%)$ & $<0.001$ \\
Cervical adenopathy & $61(79.0 \%)$ & $1(4.0 \%)$ & 0.002 \\
Changes in the peripheral extremities & $50(64.0 \%)$ & 0 & 0.020 \\
Resistance to first IVIG & $12(16.0 \%)$ & $4(16.6 \%)$ & $2(8.3 \%)$ \\
Echocardiography & & $2(8.3 \%)$ & 0.045 \\
Coronary artery dilatation & $4(5.2 \%)$ & $1(4.2 \%)$ & 0.696 \\
Increased perivascular echogenicity & $12(15.6 \%)$ & 0.464 \\
Vascular irregularity & $12(15.6 \%)$ & $7(9.1 \%)$ & 0.807 \\
Mitral regurgitation & $1(1.2 \%)$ & 0.486 \\
Pericardial effusion & & & \\
\hline
\end{tabular}

Data are represented as numbers (percentages).

and the dose was tapered to $3-5 \mathrm{mg} / \mathrm{kg}$ after the acute stage had passed. Twelve patients with $\mathrm{CKD}$ and one with $\mathrm{iKD}$ who failed to respond to initial IVIG therapy received a second dose of IVIG. Two cKD patients who did not respond to this second dose of IVIG were given infliximab. Eight $\mathrm{CKD}$ and six iKD patients yielded positive bacterial blood cultures.

Forty-one patients were enrolled as controls; the maleto-female ratio was 2.15. The mean age was $2.8 \pm 1.9$ years (range, 11 months to 8.0 years) and the mean body weight $16.5 \pm 11.1 \mathrm{~kg}$. Neither gender nor duration of fever differed significantly among the three groups. The clinical diagnoses of controls were as follows: pneumonia $(n=21)$, bacteremia $(n=5)$, acute tonsillitis $(n=4)$, cervical lymphadenitis $(n=2)$, acute bronchiolitis $(n=2)$, acute gastroenteritis $(n=$ $2)$, acute epiglottitis $(n=2)$, bacterial keratoconjunctivitis $(n=1)$, acute otitis media $(n=1)$, and acute cellulitis $(n=1)$. Only two control patients yielded positive bacterial blood cultures.

3.2. Clinical Presentations in Patients with Kawasaki Disease. At admission, of the 77 patients with $c K D, 74$ (96\%) had bilateral bulbar conjunctival infections, 71 (92\%) a polymorphous rash, 73 (94\%) changes in the oral mucosa, $61(79 \%)$ cervical adenopathy with lymph nodes greater than $1.5 \mathrm{~cm}$ in diameter, and $50(64 \%)$ changes in the peripheral extremities. Among 24 patients with iKD, 21 (87\%) had bilateral bulbar conjunctival infections, 15 (62\%) rash, 18 (75\%) changes in the oral mucosa, 7 (29\%) cervical adenopathy, and 7 (29\%) changes in the peripheral extremities. All clinical features except bilateral bulbar conjunctival infection were significantly more prevalent in $\mathrm{cKD}$ than in $\mathrm{iKD}$ patients (Table 2).

3.3. Two-Dimensional Echocardiographic Findings in Patients with Kawasaki Disease. The basic echocardiographic findings are summarized in Table 2. The EFs (derived using the cubed method) in the cKD group were $56.9 \pm 28.6 \%$ (D0),
$57.3 \pm 30.0 \%$ (D2), $61.5 \pm 28.6 \%$ (D14), and $51.7 \pm 34.6 \%$ (D56). The EFs in the iKD group were $64.6 \pm 23.5 \%$ (D0), $62.4 \pm 27.7 \%$ (D2), $64.4 \pm 24.1 \%$ (D14), and $65.1 \pm 59.4 \%$ (D56). No significant between-group difference was evident. The number of patients with dilatation of the coronary artery was significantly greater in $\mathrm{cKD}$ than in $\mathrm{iKD}$ patients (four [5.2\%] versus nil).

3.4. Laboratory Findings at the Time of Diagnosis and Changes over Time. Laboratory data obtained at the time of diagnosis are shown in Table 2. Peripheral blood from all $101 \mathrm{KD}$ patients was drawn on D0, D2, D14, and D56 and from the 41 controls on D0 and D2.

On D0, the WBC $(P=0.004)$ and platelet count $(P=$ $0.001)$, the ESR $(P<0.001)$, and the NT proBNP level $(P=0.021)$ were significantly higher in $\mathrm{KD}$ patients than controls. CRP $(P=0.004)$ and troponin I $(P=0.006)$ levels were significantly higher in the $\mathrm{CKD}$ group than controls. The hematocrit was significantly lower in the $\mathrm{iKD}$ group than controls $(P=0.028)$. The potassium concentration was significantly higher in the iKD group than in either the $\mathrm{CKD}$ or control groups $(P=0.006)$. The laboratory data from all three groups at diagnosis (D0) are shown in Table 3.

On D2, the total protein level was significantly higher in the $\mathrm{cKD}$ group than in $\mathrm{iKD}$ patients or controls $(P=$ 0.001). To explore the significance of this finding, we sought to correlate total protein levels with the total IVIG dose, body weight, and body surface area. No correlation was evident, and further work in this area is required. On D14, both platelet $(P=0.002)$ and albumin levels $(P=0.001)$ were significantly higher in $\mathrm{CKD}$ than in $\mathrm{iKD}$ patients. No significant difference in any of the WBC, the ESR, or CRP and NT proBNP levels was evident between $\mathrm{CKD}$ and $\mathrm{iKD}$ patients at any later time.

$\mathrm{cKD}$ and $\mathrm{iKD}$ patients experienced significant reductions in the WBC and CRP level at D2, D14, and D56, compared to the D0 findings. The NT-proBNP levels of cKD patients at D2 and D14 were significantly lower than those at D0 (Figure 1). 
TABLE 3: Laboratory findings at diagnosis in patients with Kawasaki disease (KD) and controls.

\begin{tabular}{|c|c|c|c|}
\hline & $\begin{array}{c}\text { Complete KD } \\
n=77\end{array}$ & $\begin{array}{c}\text { Incomplete KD } \\
n=24\end{array}$ & $\begin{array}{c}\text { Control } \\
n=41\end{array}$ \\
\hline White blood cell count $\left(/ \mathrm{mm}^{3}\right)$ & $14,689 \pm 4,848$ & $14,774 \pm 4,534$ & $11,520 \pm 5,517^{*, \S}$ \\
\hline Neutrophil proportion (\%) & $65.6 \pm 15.7$ & $59.8 \pm 16.5$ & $59.0 \pm 17.7$ \\
\hline Eosinophil proportion (\%) & $5.4 \pm 22.1$ & $1.8 \pm 1.6$ & $0.9 \pm 1.3$ \\
\hline Hemoglobin (g/dL) & $11.2 \pm 1.1$ & $10.9 \pm 1.3$ & $11.6 \pm 1.2$ \\
\hline Hematocrit (\%) & $33.2 \pm 3.0$ & $32.3 \pm 3.5$ & $34.5 \pm 3.5^{\S}$ \\
\hline Platelets $\left(10^{3} / \mathrm{mm}^{3}\right)$ & $341.4 \pm 100.4$ & $365.7 \pm 129.8$ & $275.7 \pm 89.4^{*, \mathfrak{S}}$ \\
\hline Erythrocyte sedimentation rate $(\mathrm{mm} / \mathrm{h})$ & $64.7 \pm 27.9$ & $69.2 \pm 36.5$ & $30.2 \pm 17.3^{*, \S}$ \\
\hline C-reactive protein $(\mathrm{mg} / \mathrm{dL})$ & $8.2 \pm 5.0$ & $7.6 \pm 5.5$ & $5.2 \pm 3.3^{*}$ \\
\hline Aspartate aminotransferase (U/L) & $68.8 \pm 85.8$ & $46.2 \pm 66.0$ & $67.6 \pm 109.6$ \\
\hline Alanine aminotransferase (U/L) & $76.4 \pm 105.9$ & $50.3 \pm 51.3$ & $37.5 \pm 71.5$ \\
\hline Total protein $(\mathrm{g} / \mathrm{dL})$ & $6.5 \pm 0.7$ & $6.3 \pm 0.6$ & $6.7 \pm 0.4$ \\
\hline Albumin (g/dL) & $3.7 \pm 0.5$ & $3.7 \pm 0.5$ & $3.8 \pm 0.5$ \\
\hline Sodium $(\mathrm{mEq} / \mathrm{L})$ & $135.8 \pm 2.9$ & $136.2 \pm 2.2$ & $137.0 \pm 2.7$ \\
\hline Potassium $(\mathrm{mEq} / \mathrm{L})$ & $4.3 \pm 0.4$ & $4.5 \pm 0.6^{\dagger}$ & $4.1 \pm 0.5^{\S}$ \\
\hline Chloride $(\mathrm{mEq} / \mathrm{L})$ & $101.3 \pm 12.5$ & $103.8 \pm 2.7$ & $103.9 \pm 2.9$ \\
\hline Creatine kinase (IU/L) & $125.1 \pm 216.4$ & $61.3 \pm 46.6$ & $99.0 \pm 35.6$ \\
\hline Creatine kinase-MB (ng/mL) & $15.2 \pm 11.7$ & $11.6 \pm 11.1$ & $15.2 \pm 11.1$ \\
\hline Myoglobin (ng/mL) & $10.7 \pm 23.5$ & $12.9 \pm 18.4$ & $3.8 \pm 9.6$ \\
\hline Troponin I (ng/mL) & $0.013 \pm 0.010$ & $0.013 \pm 0.013$ & $0.003 \pm 0.005^{*}$ \\
\hline $\mathrm{N}$-terminal pro $\mathrm{BNP}(\mathrm{pg} / \mathrm{mL})$ & $2,237.4 \pm 5043.4$ & $1,391.5 \pm 2021.9$ & $323.6 \pm 442.2^{*, \$}$ \\
\hline
\end{tabular}

KD: Kawasaki disease. Data are shown as means $\pm \mathrm{SD} .{ }^{\dagger} P<0.05$, complete Kawasaki versus incomplete Kawasaki disease; ${ }^{*} P<0.05$, complete Kawasaki disease versus control; ${ }^{\S} P<0.05$, incomplete Kawasaki disease versus control.

3.5. Serum Procalcitonin Levels at the Time of Diagnosis and Changes over Time. Of the $101 \mathrm{KD}$ patients and 41 controls, we measured serum procalcitonin levels of 85 patients (cKD: 64, iKD: 21) and 34 controls at D0. The mean D0 serum procalcitonin levels in $\mathrm{cKD}$ patients $(0.71 \pm 1.36 \mathrm{ng} / \mathrm{mL})$ and controls $(0.67 \pm 1.06 \mathrm{ng} / \mathrm{mL})$ were significantly higher than those of $\mathrm{iKD}$ patients $(0.26 \pm 0.26 \mathrm{ng} / \mathrm{mL})(P=0.014$ and $P=0.041$, resp.) (Figure 2).

We measured D2 serum procalcitonin levels in 82 patients (cKD: 65, iKD: 17) and 15 controls (after resolution of fever); D14 levels in 85 patients (cKD: 66, iKD: 19); and D56 levels in 22 patients (cKD: 18, iKD: 4). The mean control procalcitonin level $(0.30 \pm 1.33 \mathrm{ng} / \mathrm{mL})$ at $\mathrm{D} 2$ was significantly higher than that of the iKD group $(0.14 \pm 1.10 \mathrm{ng} / \mathrm{mL})(P=0.035)$. However, no significant difference in mean serum procalcitonin level was evident between $\mathrm{CKD}$ and $\mathrm{iKD}$ patients at any later time.

cKD patients showed significant reductions in procalcitonin levels at D14 $(P<0.001)$ and D56 $(P<0.001)$ compared to D0. Likewise, iKD patients experienced significant reductions at D2 $(P=0.028)$ and D14 $(P=0.004)$ (Figure 2). No significant difference was evident between the four $\mathrm{CKD}$ patients with coronary artery dilatation $(0.8 \pm 1.0 \mathrm{~mm})$ and those without dilatation $(0.7 \pm 1.4 \mathrm{~mm})$. Also, no significant correlation was evident between procalcitonin level and the presence of a coronary artery lesion at any later time. However, a lack of statistical power may have precluded identification of such a correlation; very few patients had coronary artery dilatation.

\section{Discussion}

In the present study, we have shown the utility of measuring serum procalcitonin levels in patients with $\mathrm{cKD}$, $\mathrm{iKD}$, and other febrile illnesses, at different stages of disease. KD patients had significantly higher WBC and platelet counts and ESR than did those with other febrile illnesses. Also, during the acute stage of disease, $\mathrm{CKD}$ patients and those with other febrile illnesses had significantly higher levels of serum procalcitonin than did $\mathrm{iKD}$ patients.

Procalcitonin has been suggested to be an acute-phase reactant, because synthesis thereof is thought to be induced by IL- 6 or TNF- $\alpha$, and procalcitonin levels increase after development of inflammation $[13,17]$. Although CRP is a sensitive marker of inflammation, CRP levels rise and then become normalized, only at later stages of disease. Also, CRP levels cannot be used to predict the presence of infection [18]. Several studies have reported high procalcitonin levels in the absence of infection in patients with Behcet's disease, $\mathrm{KD}$, and active Wegener's granulomatosis [14, 19-21]. Okada et al. [14] suggested that procalcitonin level could serve as a novel marker for clinical diagnosis of $\mathrm{KD}$. The serum concentration of procalcitonin was significantly higher in 25 acute $\mathrm{KD}$ patients $(2.3 \pm 3.0 \mathrm{ng} / \mathrm{mL})$ and 17 with bacterial infections $(2.2 \pm 2.9 \mathrm{ng} / \mathrm{mL})$ than in patients with autoimmune diseases $(n=10,0.4 \pm 0.4 \mathrm{ng} / \mathrm{mL})$ or viral infections $(n=17,0.4 \pm$ $0.3 \mathrm{ng} / \mathrm{mL})$, or healthy children $(n=18,0.2 \pm 0.1)$. The cited authors concluded that the serum procalcitonin level may be of clinical utility when determining the severity of $\mathrm{KD}$ 


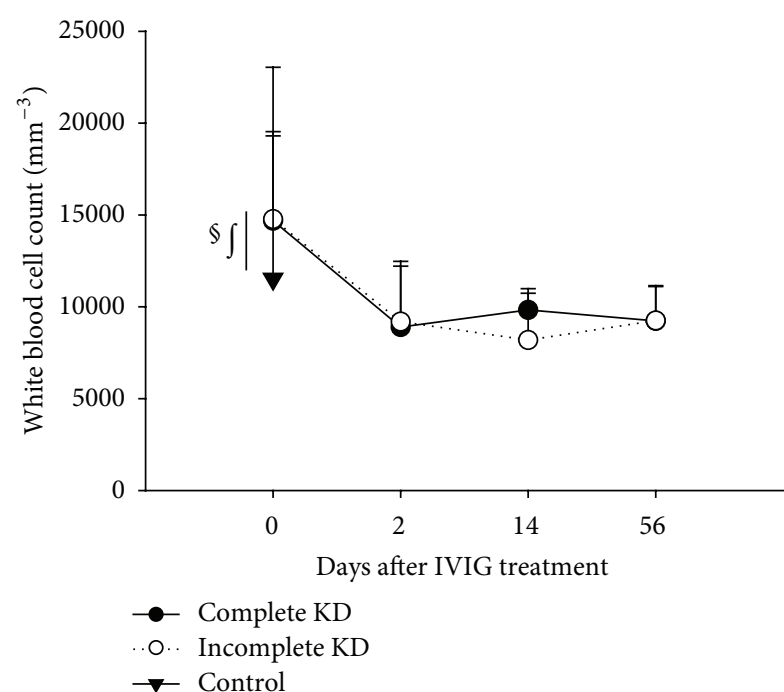

(a)

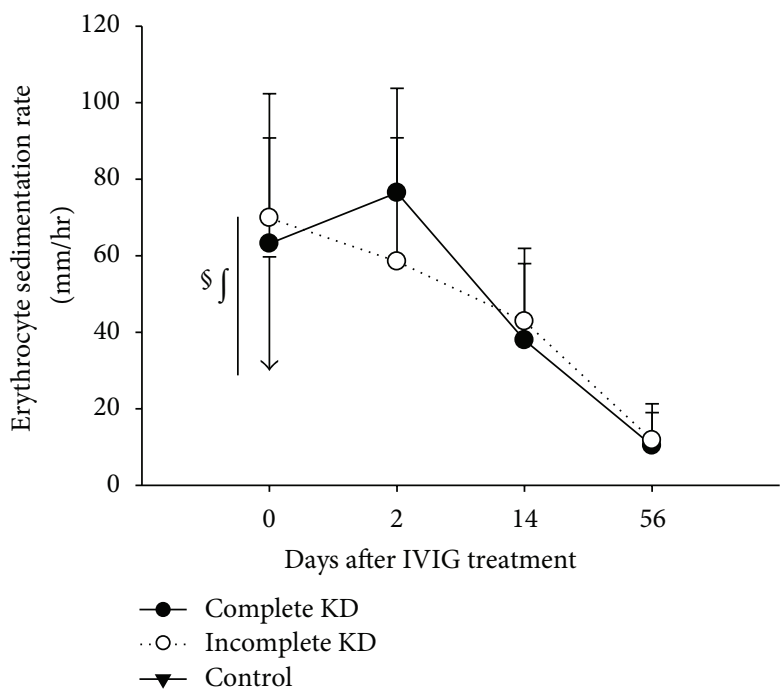

(c)

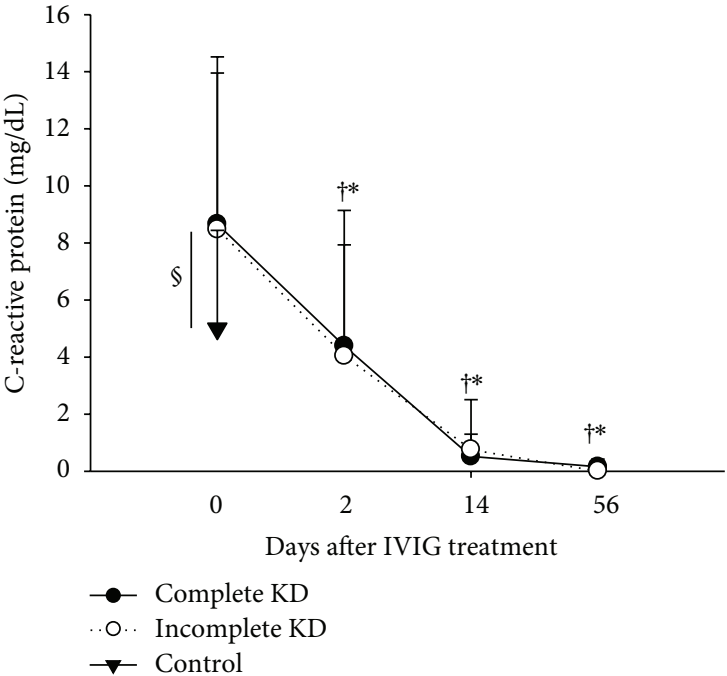

(b)

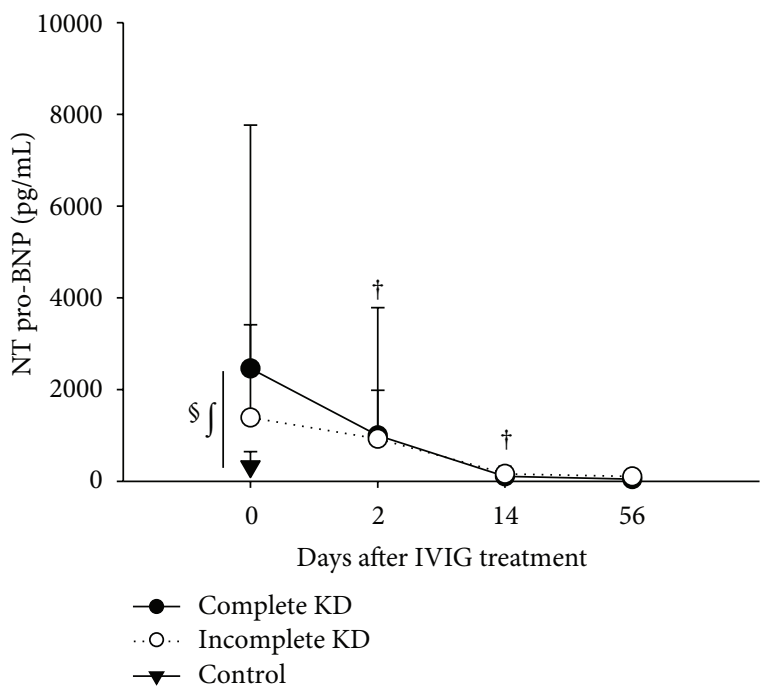

(d)

FIGURE 1: Laboratory data from patients with complete Kawasaki disease (KD), incomplete KD, and other febrile illnesses (controls), collected on the day of diagnosis and 2, 14, and 56 days after intravenous immunoglobulin (IVIG) treatment. (a) White blood cell count, (b) C-reactive protein level, (c) erythrocyte sedimentation rate, and (d) N-terminal pro-brain natriuretic protein (NT-proBNP) level. ${ }^{\dagger} P<0.05$ versus day of diagnosis in children with complete $\mathrm{KD},{ }^{*} P<0.05$ versus day of diagnosis in children with incomplete KD. ${ }^{\S} P<0.05$; a statistically significant difference was evident between the complete $\mathrm{KD}$ group and controls. ${ }^{\int} P<0.05$; a statistically significant difference was evident between the incomplete KD group and controls.

and might assist in the differential diagnosis of patients with inflammatory diseases. It was also found that four patients who developed coronary aneurysms exhibited higher procalcitonin levels $(7.2 \pm 3.8 \mathrm{ng} / \mathrm{mL})$ [14]. Procalcitonin levels are not elevated in patients with inflammatory (including autoimmune) diseases, but the levels of other acute phase reactants including CRP, IL-6 and/or neopterin may indeed be higher than normal $[22,23]$.

In contrast, Chakrabartty and Apong reported that KD patients expressed low levels of procalcitonin [15]. The cited authors sought a marker assisting in differentiation of $\mathrm{KD}$ from sepsis so that $\mathrm{KD}$ patients would not be unnecessarily prescribed antibiotics. Procalcitonin levels were low $(<0.5 \mathrm{ng} / \mathrm{mL})$ in all of 38 admitted KD patients, but all had high ESRs and CRP levels [15].

In our present study, we considered that procalcitonin was an acute-phase reactant and compared the levels thereof in patients with both types of $\mathrm{KD}$ and controls with other febrile illnesses. During the acute stage of disease, procalcitonin levels were significantly higher in patients with $\mathrm{cKD}$ and other febrile illnesses than in $\mathrm{iKD}$ patients, decreased in both types of KD patients to D14 after IVIG treatment, and remained steady thereafter. No statistically significant correlation between the presence of coronary artery disease 


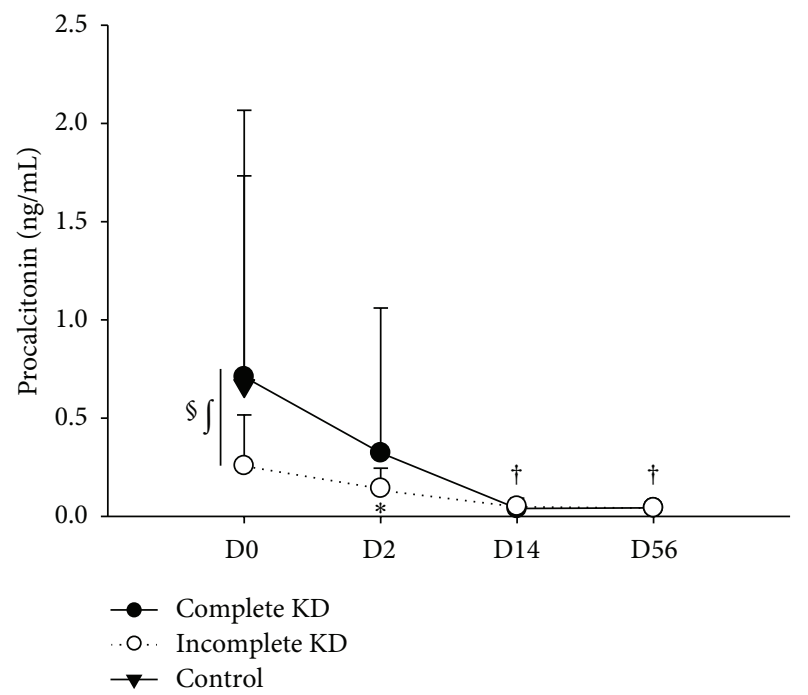

FIGURE 2: Differences in procalcitonin levels among patients with complete Kawasaki disease (KD), incomplete KD, and other febrile illnesses (controls), on the day of diagnosis and 2, 14, and 56 days after intravenous immunoglobulin (IVIG) treatment. ${ }^{\dagger} P<0.05$ versus day of diagnosis in children with complete $\mathrm{KD},{ }^{*} P<0.05$ versus day of diagnosis in children with incomplete $\mathrm{KD}$. ${ }^{\S} \mathrm{P}<0.05$; a statistically significant difference was evident between the complete and incomplete $\mathrm{KD}$ groups. ${ }^{\int_{P}}<0.05$; a statistically significant difference was evident between the control and incomplete $\mathrm{KD}$ groups.

and procalcitonin level was evident although, as explained above, our analysis may have lacked adequate statistical power. The observed differences in procalcitonin levels may be explained by the fact that $\mathrm{cKD}$ patients exhibit more advanced inflammatory reactions than do iKD patients. This pathophysiologic feature of KD requires further study. In the present work, we found that serum procalcitonin levels were relatively low in both $\mathrm{cKD}(0.71 \pm 1.36 \mathrm{ng} / \mathrm{mL})$ and iKD $(0.26 \pm 0.26 \mathrm{ng} / \mathrm{mL})$ patients compared with the level $(2.3 \pm 3.0 \mathrm{ng} / \mathrm{mL})$ reported by Okada et al. [14]. One possible explanation is that the cited authors worked with only 25 patients; we studied 101. Also, a relatively small proportion (4\%) of our patients had coronary artery lesions, compared to $25 \%$ of patients in the cited study. Chakrabartty and Apong reported low procalcitonin levels $(<0.5 \mathrm{ng} / \mathrm{mL})$ in their $38 \mathrm{KD}$ patients [15].

Several well-known laboratory findings support the diagnosis of either iKD or cKD. Most KD patients have an elevated CRP level or ESR [24], and an elevated NT-proBNP level at the acute stage of KD appears to be a reliable indicator of the presence of either cKD or iKD $[25,26]$. A recent large-scale study by Manlhiot et al. [12] showed that $\mathrm{cKD}(n=738)$ and iKD $(n=217)$ patients yielded similar laboratory findings in terms of WBC, ESR and albumin, AST, and CRP levels but not ALT levels. The level of ALT in cKD patients (median: $27 \mathrm{U} / \mathrm{L}$, range: $4-328 \mathrm{U} / \mathrm{L}$ ) was higher than in patients with iKD (median: $22 \mathrm{U} / \mathrm{L}$, range: $2-154 \mathrm{U} / \mathrm{L} ; P=0.02$ ) [12]. Perrin et al. [27] reported that the serum levels of both ALT and gamma-glutamyltransferase were significantly higher in 39 patients with cKD $(67.1 \pm 91.1 \mathrm{U} / \mathrm{L}, 75.9 \pm 74.6 \mathrm{U} / \mathrm{L}$, resp.) than in 20 patients with $\mathrm{iKD}(37.6 \pm 21.8 \mathrm{U} / \mathrm{L}, 31.2 \pm 31.8 \mathrm{U} / \mathrm{L}$, resp.). However, none of CRP or ESR and blood cell count (including WBC) differed significantly between $\mathrm{CKD}$ and $\mathrm{iKD}$ patients at admission.

In our present study, WBC and platelet count and the ESR were significantly higher in $\mathrm{KD}$ patients compared to those with other febrile illnesses, at the time of diagnosis. Also, in the subacute stage, WBC and platelet counts, the ESR, and the CRP level were significantly higher in KD patients than controls. The total protein level was significantly higher in the cKD than in the iKD or control groups and was not correlated with any of IVIG dose, body weight, or body surface area. This finding requires further study. However, none of the WBC, the ESR, or the levels of CRP and NT-proBNP differed significantly between $\mathrm{CKD}$ and $\mathrm{iKD}$ patients. None of the levels of total protein, albumin, AST, ALT, sodium, or chloride differed significantly among the two KD groups and controls. Only serum potassium level (in the iKD group) was significantly higher than in the cKD group and controls.

One limitation of the present study is that some follow-up data are missing probably because parents refused to permit blood to be drawn as recovering children appeared to be healthy.

In conclusion, this is the first report of serial procalcitonin measurements in patients with both types of KD and controls. The mean D0 serum procalcitonin levels of $\mathrm{CKD}$ and controls were significantly higher than those of $\mathrm{iKD}$ patients during the acute stage of disease. In contrast, the levels of other inflammatory markers including the WBC, the ESR, and CRP level did not significantly differ between patients with $\mathrm{cKD}$ and iKD. Further exploration of differences in procalcitonin levels between $\mathrm{cKD}$ and $\mathrm{iKD}$ patients is needed to better understand the incomplete presentation of $\mathrm{iKD}$.

\section{Conflict of Interests}

The authors have no conflict of interest to disclose.

\section{Acknowledgment}

This study was supported by a Grant (CRI 10-027-1) of the Chonnam National University hospital Research Institute of Clinical Medicine.

\section{References}

[1] S. T. Shulman and A. H. Rowley, "Advances in Kawasaki disease," European Journal of Pediatrics, vol. 163, no. 6, pp. 285-291, 2004.

[2] J. C. Burns and M. P. Glodé, "Kawasaki syndrome," The Lancet, vol. 364, no. 9433, pp. 533-544, 2004.

[3] D. S. Kim, “Kawasaki disease," Yonsei Medical Journal, vol. 47, no. 6, pp. 759-772, 2006.

[4] Y. Nakamura, M. Yashiro, R. Uehara, I. Oki, M. Watanabe, and H. Yanagawa, "Epidemiologic features of Kawasaki disease in Japan: results from the nationwide survey in 2005-2006," Journal of Epidemiology, vol. 18, no. 4, pp. 167-172, 2008. 
[5] J. Fukushige, N. Takahashi, Y. Ueda, and K. Ueda, "Incidence and clinical features of incomplete Kawasaki disease," Acta Paediatrica, vol. 83, no. 10, pp. 1057-1060, 1994.

[6] A. Joffe, A. Kabani, and T. Jadavji, "Atypical and complicated Kawasaki disease in infants-do we need criteria?" Western Journal of Medicine, vol. 162, no. 4, pp. 322-327, 1995.

[7] E. D. Belay, R. A. Maddox, R. C. Holman, A. T. Curns, K. Ballah, and L. B. Schonberger, "Kawasaki syndrome and risk factors for coronary artery abnormalities: United States, 1994-2003," Pediatric Infectious Disease Journal, vol. 25, no. 3, pp. 245-249, 2006.

[8] M. S. Wilder, L. A. Palinkas, A. S. Kao, J. F. Bastian, C. L. Turner, and J. C. Burns, "Delayed diagnosis by physicians contributes to the development of coronary artery aneurysms in children with Kawasaki syndrome," Pediatric Infectious Disease Journal, vol. 26, no. 3, pp. 256-260, 2007.

[9] K. S. Ha, G. Jang, J. Lee et al., "Incomplete clinical manifestation as a risk factor for coronary artery abnormalities in Kawasaki disease: a meta-analysis," European Journal of Pediatrics, vol. 172, no. 3, pp. 343-349, 2013.

[10] J. J. Yu, "Diagnosis of incomplete Kawasaki disease," Korean Journal of Pediatrics, vol. 55, no. 3, pp. 83-87, 2012.

[11] E. S. Yellen, K. Gauvreau, M. Takahashi et al., "Performance of 2004 American Heart Association recommendations for treatment of Kawasaki disease," Pediatrics, vol. 125, no. 2, pp. e234e241, 2010.

[12] C. Manlhiot, E. Christie, B. W. McCrindle, H. Rosenberg, N. Chahal, and R. S. M. Yeung, "Complete and incomplete Kawasaki disease: two sides of the same coin," European Journal of Pediatrics, vol. 171, no. 4, pp. 657-662, 2012.

[13] B. Al-Nawas, I. Krammer, and P. M. Shah, "Procalcitonin in diagnosis of severe infections," European Journal of Medical Research, vol. 1, no. 7, pp. 331-333, 1996.

[14] Y. Okada, H. Minakami, T. Tomomasa et al., "Serum procalcitonin concentration in patients with Kawasaki disease," Journal of Infection, vol. 48, no. 2, pp. 199-205, 2004.

[15] S. Chakrabartty and S. Apong, "Procalcitonin estimation in Kawasaki disease," Indian Pediatrics, vol. 46, no. 7, p. 648, 2009.

[16] B. W. McCrindle, J. S. Li, L. L. Minich et al., "Coronary artery involvement in children with Kawasaki disease: risk factors from analysis of serial normalized measurements," Circulation, vol. 116, no. 2, pp. 174-179, 2007.

[17] M. W. N. Nijsten, P. Olinga, T. H. The et al., "Procalcitonin behaves as a fast responding acute phase protein in vivo and in vitro," Critical Care Medicine, vol. 28, no. 2, pp. 458-461, 2000.

[18] B. M. Ertugrul, A. Yilmabasar, O. Ertugrul, H. B. Ayabakan, S. Kizilirmak, and S. Turkmen, "Do C-reactive protein and procalcitonin predict hospital-acquired infection in patients with trauma?" Saudi Medical Journal, vol. 27, no. 4, pp. 560-562, 2006.

[19] G. Conti, A. Amore, M. Chiesa et al., "Procalcitonin as a marker of micro-inflammation in hemodialysis," Journal of Nephrology, vol. 18, no. 3, pp. 282-288, 2005.

[20] B. Adam and E. Calikoglu, "Serum interleukin-6, procalcitonin and C-reactive protien levels in subjects with active Behçet's disease," Journal of the European Academy of Dermatology and Venereology, vol. 18, no. 3, pp. 318-320, 2004.

[21] F. Moosig, E. Csernok, E. Reinhold-Keller, W. Schmitt, and W. L. Gross, "Elevated procalcitonin levels in active Wegener's granulomatosis," Journal of Rheumatology, vol. 25, no. 8, pp. 1531-1533, 1998.
[22] V. Schwenger, J. Sis, A. Breitbart, and K. Andrassy, "CRP levels in autoimmune disease can be specified by measurement of procalcitonin," Infection, vol. 26, no. 5, pp. 274-276, 1998.

[23] O. K. Eberhard, M. Haubitz, F. M. Brunkhorst, V. Kliem, K. M. Koch, and R. Brunkhorst, "Usefulness of procalcitonin for differentiation between activity of systemic autoimmune disease (systemic lupus erythematosus/systemic antineutrophil cytoplasmic antibody-associated vasculitis) and invasive bacterial infection," Arthritis and Rheumatism, vol. 40, no. 7, pp. 12501256, 1997.

[24] J. W. Newburger, M. Takahashi, M. A. Gerber et al., "Diagnosis, treatment, and long-term management of Kawasaki disease: a statement for health professionals from the Committee on Rheumatic Fever, Endocarditis and Kawasaki Disease, Council on Cardiovascular Disease in the Young, American Heart Association," Pediatrics, vol. 114, no. 6, pp. 1708-1733, 2004.

[25] N. Dahdah, A. Siles, A. Fournier et al., "Natriuretic peptide as an adjunctive diagnostic test in the acute phase of Kawasaki disease," Pediatric Cardiology, vol. 30, no. 6, pp. 810-817, 2009.

[26] A. McNeal-Davidson, A. Fournier, L. Spigelblatt et al., "Value of amino-terminal pro B-natriuretic peptide in diagnosing Kawasaki disease," Pediatrics International, vol. 54, no. 5, pp. 627-633, 2012.

[27] L. Perrin, A. Letierce, C. Guitton, T.-A. Tran, V. Lambert, and I. Koné-Paut, "Comparative study of complete versus incomplete Kawasaki disease in 59 pediatric patients," Joint Bone Spine, vol. 76, no. 5, pp. 481-485, 2009. 


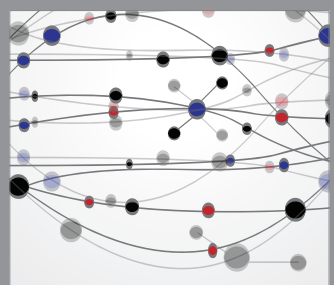

The Scientific World Journal
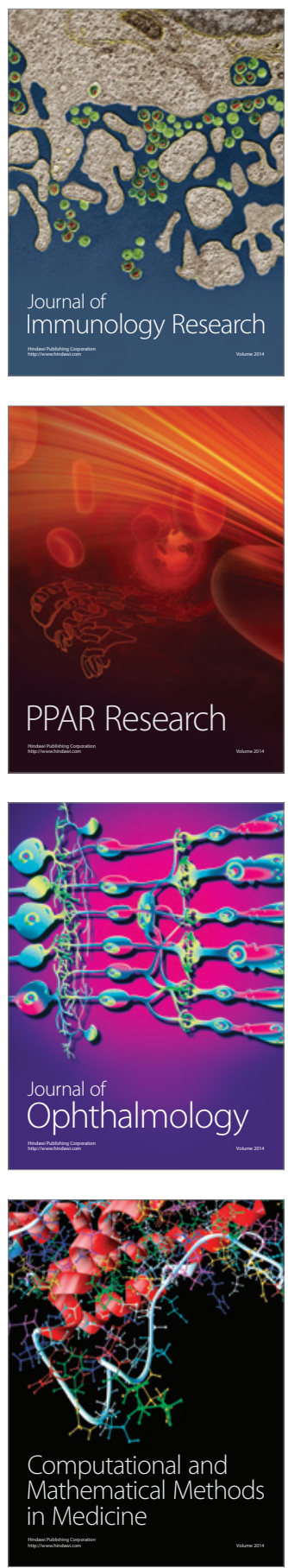

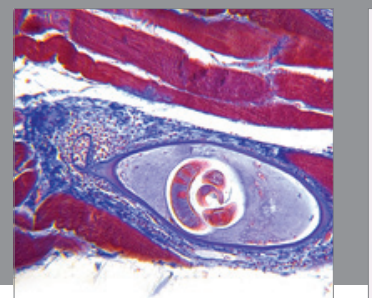

Gastroenterology

Research and Practice
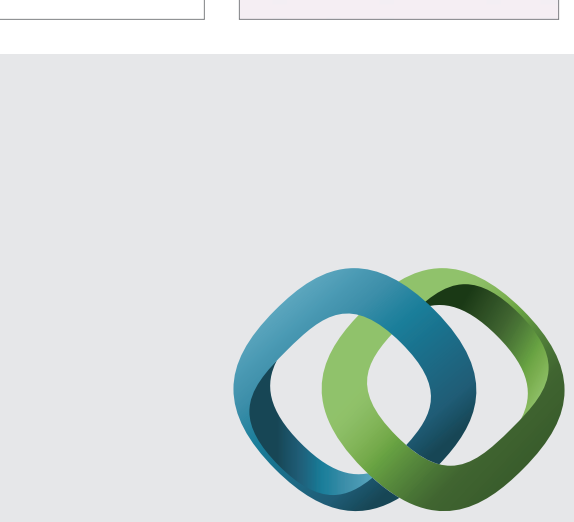

\section{Hindawi}

Submit your manuscripts at

http://www.hindawi.com
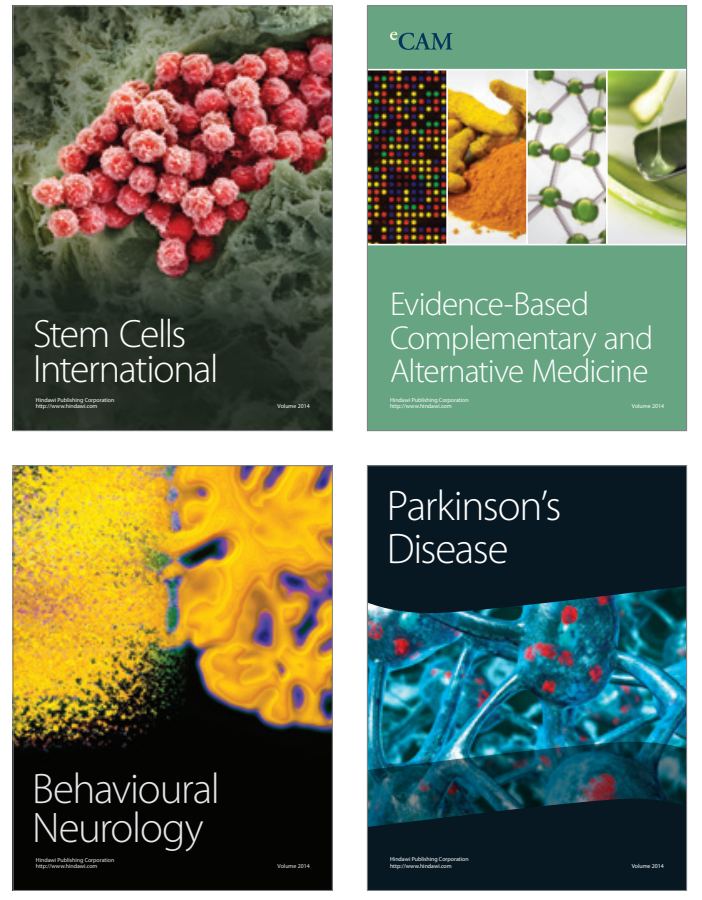
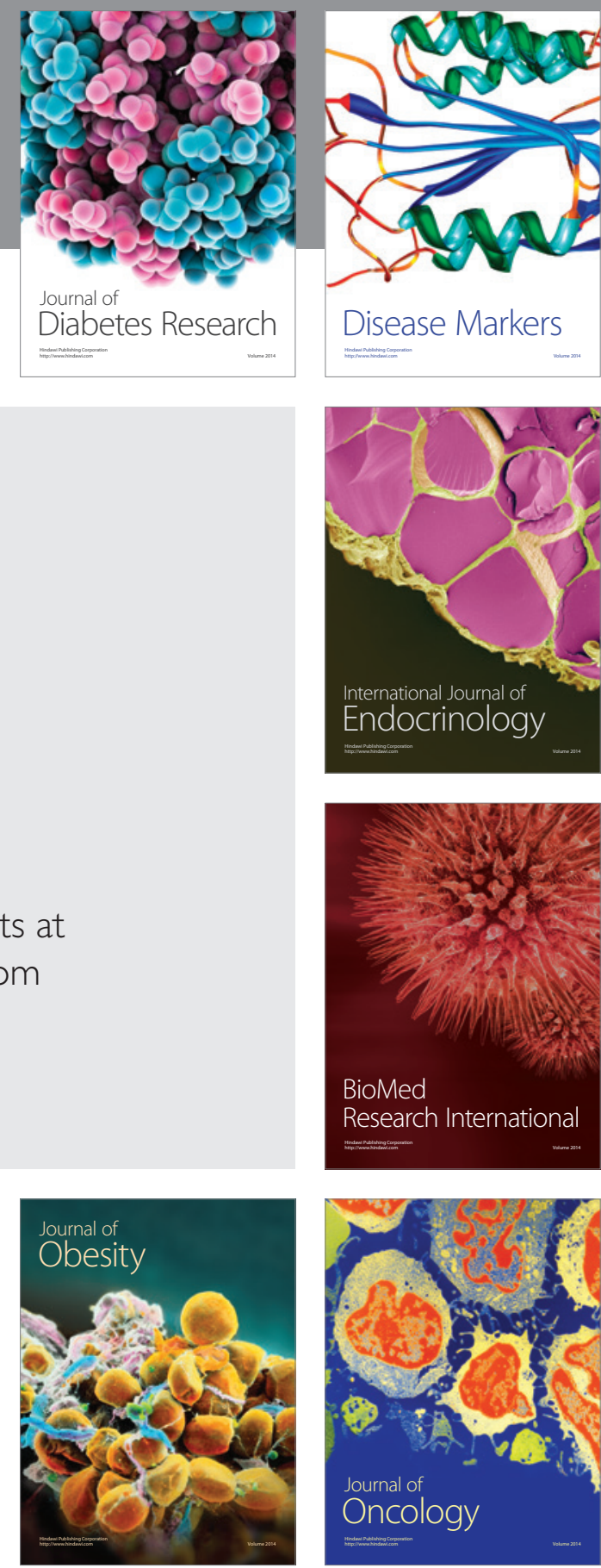

Disease Markers
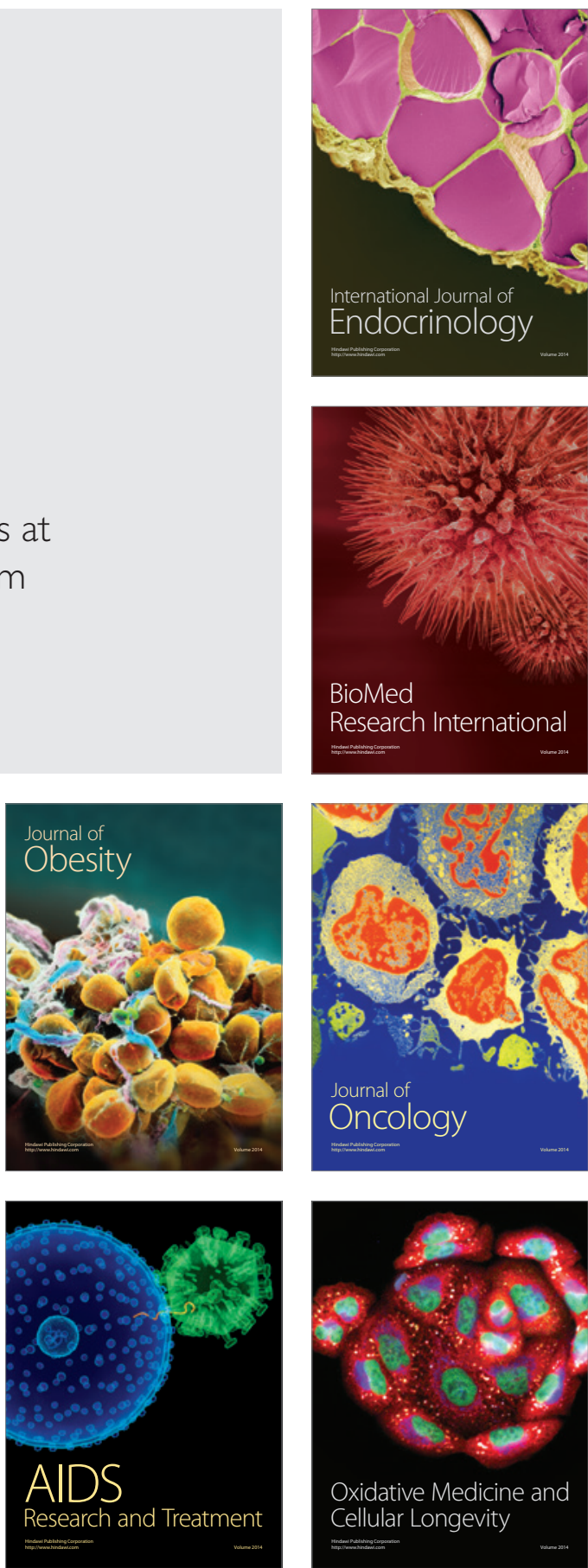